\title{
Interactive comment on "AtChem, an open source box-model for the Master Chemical Mechanism" by Roberto Sommariva et al.
}

\section{Anonymous Referee \#2}

Received and published: 12 October 2019

\section{General comments}

The paper describes a new open-source box model designed primarily for runs using the Master Chemical Mechanism (MCM), although other mechanisms can also be modelled provided they are entered in the correct format. The model comes in two forms, one (the original) available online via a web-interface, and a downloadable one (AtChem2) suitable for more advanced studies including batch runs that can be executed on the user's machine. The box model is presented as being free and easy to use, and having functionality that makes it particularly suitable for comparison against observational data, due to the way it handles constrained variables with different time frequencies. It is applied in two case studies to chamber and field data respectively to 
illustrate that it can handle these scenarios and allow us to reach some conclusions about which parts of the mechanism need to be reviewed.

I believe this paper will be suitable for publication subject to revision.

\section{Specific comments}

The text in the paper is generally well-written and easy to follow. The figures are less clear, however. In particular, Figure 2 is too small to make much sense of even when zoomed in on (due to the scale); the outlier marker is larger than some of the boxand-whiskers. Figure 3 is missing some arrowheads, and the ones that are there are too small to be clearly seen. In Figure 6, the ozone and nitrogen oxides lines/markers are not labelled as to which is which; I would also recommend using different marker shapes when presenting multiple datasets in one graph in addition to using different colours.

I think the paper could highlight in detail what makes AtChem stand out over specific other box models. The two forms (online/offline) appear to have different unique benefits, and perhaps need to be discussed separately. It appears that the online model can at present only be run with login details (is it only for use by the EUROCHAMP community?), which might restrict takeup (especially for teaching purposes), but I hope this is something the authors are planning to address. I also note that the online form does not seem to readily support the newest MCM version; perhaps this can be updated?

Parts of the paper are using different versions of the MCM and perhaps also different versions of AtChem(2). In particular, on page 12 the section on lines 358-360 describes that the previously published results were off by a small amount due to a bug in a previous version of AtChem; however, at no point does the paper make reference to which version(s) of AtChem(2) were used in the runs. I would suggest carrying out all the model runs with the latest version of AtChem2 and annotating them as such. If

Printer-friendly version

Discussion paper 
the latest MCM version was not used for modelling the field study data for consistency with the previous paper analysing this data, I would comment on this, but also perhaps rerun the simulation with the newest MCM version for comparison.

\section{Technical corrections}

p7, line 204: change "studies" to "study"

p7, line 214: change "results" to "result" and correct spelling of "stiffness"

p8, line 224: Eq. 3 appears to use two different forms of the multiplication sign

p12, line 351: IUPAC spelling is "sulfide"

p22, label on Figure 4: the local time is GMT-7 in the winter, but GMT-6 in the summer due to daylight saving time

p27, in Table 1: "SO2" should have 2 as a subscript

There is inconsistent use of American and British spellings $(\mathrm{s} / \mathrm{z})$ in the manuscript, and though it is a very minor issue, this can perhaps be standardised. I also feel that a few more hyphens would aid easy parsing of the text in places (e.g. p7, line 205 as well as Figure 2 label: "9-days"; p9, line 250 as well as p8, line 226: "two-stream").

Interactive comment on Geosci. Model Dev. Discuss., https://doi.org/10.5194/gmd-2019-192, 2019. 